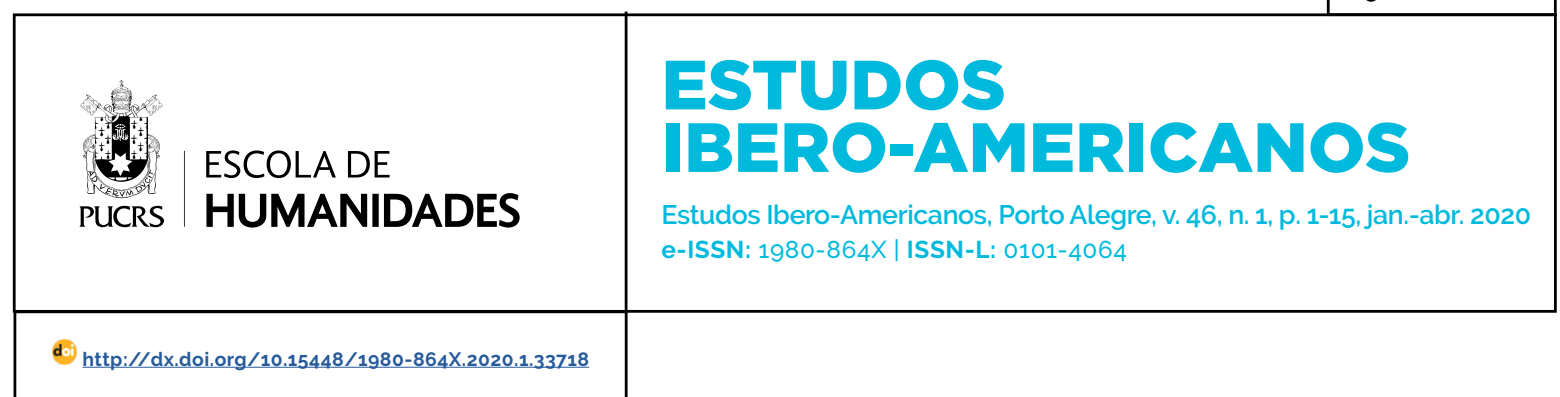

\title{
As fronteiras geopolíticas do condomínio Panamazônico: observações epistemológicas
}

The Geopolitical Boundaries of the Panamazonic Condominium: epistemological comments

Las fronteras geopoliticas del Condominio Panazónico: observaciones epistemológicas

\section{Delmo de Oliveira \\ Torres Arguelhes ${ }^{1}$}

orcid.org/0000-0002-5275-4440

delmo.arguelhes@gmail.com

Recebido em: 16 abr. 2019 Aprovado em: 24 jul. 2019 Publicado em: 28 abr. 2020.
Resumo: A disciplina geopolitica sob a crítica fenomenológica. Os fundamentos da geopolítica brasileira desenvolvida por Meira Mattos e a Panamazônia. Defesa e integração da Panamazônia, desafios de integração ao pensamento geopolítico brasileiro.

Palavras-chave: Geopolítica. Fenomenologia. Amazônia brasileira.

Abstract: The geopolitical discipline under the phenomenological critique. The foundations of Brazilian geopolitics developed by Meira Mattos and Panamazonia. Defense and integration of Panamazonia, integration challenges to Brazilian geopolitical thinking.

Keywords: Geopolitics. Phenomenology. Brazilian Amazon.

Resúmen: La disciplina geopolítica bajo crítica fenomenológica. Los fundamentos de la geopolítica brasileña desarrollados por Meira Mattos y Panamazônia. Defensa e integración de Panamazonia, desafíos de integración al pensamiento geopolítico brasileño.

Palabras clave: Geopolítica. Fenomenología. Amazonía brasileña.

"Naquele império, a Arte da Cartografia alcançou tal Perfeição que o mapa de uma única provincia ocupava toda uma Cidade, e o mapa do império, toda uma provincia. Com o tempo, esses Mapas Desmesurados não foram satisfatórios e os Colégios de Cartógrafos levantaram um Mapa do Império, que tinha o tama-

nho do império e coincidia pontualmente com ele. Menos Afeitas ao Estudo da Cartografia, as Gerações Seguintes entenderam que esse dilatado Mapa era Inútil e não sem piedade o entregaram às Inclemências do Sol e dos Invernos. Nos desertos do Oeste perduram despedaçadas Ruinas do Mapa, habitadas por Animais e por Mendigos; em todo o País não há outra reliquia das Disciplinas Geográficas".

(Jorge Luis Borges, Do rigor na ciência). 


\section{Introdução}

Este excerto de Borges (1999, p. 247) levanta uma questão essencial sobre a narração descritiva rigorosa e metódica de um objeto, ou, como alguns podem preferir, científica. Ao representar um objeto, a representação torna-se outro objeto. Segundo o dicionário Houaiss, representar, neste sentido, é a "ideia ou imagem que concebemos do mundo ou de alguma coisa" (2009, p. 1648). A imagem do mapa definitivo do império foi planejada não apenas para reproduzir o real com exatidão, mas, principalmente, com majestade. 0 mapa ocupava todo o império, como um lembrete perene a todos os habitantes acerca da grandeza da entidade politica, sob a qual todos estavam submetidos. Pairava sobre a cabeça de todos os súditos, sem exceção. Assim, dois portentos se uniam: a descrição precisa e monumental e o território da entidade política.

A grandeza do império, expressa na cartografia, não seria de modo algum mero acaso ou expressão fortuita. O Estado é a organização humana territorial por excelência; o mesmo necessita marcar o espaço onde pratica o poder. Podemos definir o Estado como uma dominação política sobre uma população em um território determinado. Essa dominação estatal chama-se, grosso modo, soberania.

O próprio conceito de soberania é definido de um e do outro lado da fronteira que assinala os limites do território. Mede-se o exercício do poder, qualquer que seja a origem, a natureza, o funcionamento, pela eficácia do controlo territorial que o Estado garante, mediante os meios físicos e morais que dispõe. [...] Certamente que não existe Estado sem uma consciência colectiva que o reconheça, mas [...] um povo ou uma nação sem Estado é considerada [...] privada da sua base e expressão natural (RONCAYOLO, 1986, p. 276).

Território é essencial. As marcas na linguagem, como não poderiam deixar de ser, expressam bem a importância do território sob a égide do Estado nacional. Por exemplo, podemos destacar os termos anglófonos fatherland e motherland. $\mathrm{O}$ povo - o qual, de acordo com Johann Gottfried von Herder, é uma entidade com desenvolvimento semelhante ao organismo biológico - nasce da terra e mantém essa relação filial pela eternidade. O mapa, no texto de Borges, coloca os súditos em duas posições: sustentados pela terra, que os gerou, os alimenta e dá sentido às vidas e submetidos à terra, abaixo da representação cartográfica. A vontade de reafirmar o império uniu-se à busca de uma narrativa científica igualmente grandiosa. Por ser cientifica, não poderia ser posta em dúvida.

O pensamento nacionalista necessita em larga medida da representação territorial. Parte considerável do discurso nacionalista francês entre 1870 e 1918 narrava a perda da Alsácia Lorena como a amputação de um membro ou (em uma inversão curiosa), como a perda de um filho. Mapas lusitanos à época salazarista (193268) mostravam as então colônias de Angola e Moçambique sobrepostas ao mapa europeu, para ilustrar a assertiva que Portugal não era um pais pequeno em termos territoriais. Nas escolas brasileiras, as crianças aprendem que o Brasil é o quinto pais do mundo em tamanho territorial, ou o quarto, se considerarmos apenas as terras contiguas. Fica, entre os estudantes, a sensação que os Estados Unidos trapacearam ao comprar o território do Alaska.

Um império é muito mais agressivo em termos territoriais, do que as demais formas estatais. Busca expansão ilimitada. Pode-se pensar, como ponto de partida, o conceito de império como uma "organização hegemônica que transcenda os quadros étnicos ou politicos naturais e tenda para um certo tipo de dominação universal" (CARTIER, 1989, p. 318). A ideia de um império, portanto, remete a uma entidade aglutinadora. Uma soma de unidades menores. Versão amplificada de um 'reino', o império serve também para resolver conflitos internos, quando se mostra majestoso aos súditos. O império brasileiro (1823-89) surgiu justamente de uma sugestão do grupo maçônico ligado ao príncipe Dom Pedro. Ao contrário da historiografia conservadora brasileira, a qual narrava um Brasil homogêneo, o processo de construção do Estado nacional foi lento e demorado. E começou a partir das províncias 
do Rio de Janeiro, São Paulo e Minas Gerais. Especula-se, ainda na atualidade, que a unidade territorial imaginada a partir do atual sudeste só foi garantida pela monarquia imperial, em contraposição à fragmentação republicana da América hispânica. Nesse sentido, a imaginação geográfica tem um papel importante a cumprir.

O pensamento ocidental ao longo do século XIX tentou unir a Razão (o cientificismo positivo) com a Sensação (o nacionalismo romântico) para narrar a estrutura estatal. Os estudos das humanidades tentavam por um lado emular o grau de certeza e exatidão das ciências da natureza e por outro justificar a grandeza do Estado: história, língua e literatura nacionais. A geografia política acabou gerando um ramo especializado em planejar, cientificamente, as possibilidades de transformação de uma nação em potência, a partir do povo e do território: a geopolítica.

A disciplina geopolítica surgiu no início do século XX, sob uma dupla sombra ideológica: o cientificismo do período - o qual tendia a validar apenas o conhecimento que seguisse esses preceitos rigorosos e exatos - e o nacionalismo. ${ }^{2}$ É mais do que necessário pensar a disciplina geopolítica diante de alguns debates marcantes das humanidades do último século, incluindo a fenomenologia e a virada linguística. Diante de tal ponto de partida, o questionamento principal de nosso artigo é: como a geopolítica brasileira pensa a Panamazônia? No primeiro momento, discutiremos a disciplina geopolítica sob os aspectos epistemológicos e ontológicos, examinando pressupostos e conclusões. No segundo momento, chegaremos à integração amazônica proposta pelo Estado brasileiro. Nessas duas partes, o pensamento do general Meira Mattos será o nosso fio condutor. Tal escolha, arbitrária, foi tomada justamente pelo fato de Meira Mattos ser um dos nomes mais representativos do pensamento geopolítico brasileiro.

Edmund Husserl propunha a fenomenologia como uma filosofia ontológica, um retorno às coisas, elas mesmas (1986, p. 53). O ponto de partida seria a દ́roxウ், uma suspensão radical dos significados do objeto. A غ́roxn், nesse sentido, estabelece o que se chama de redução fenomenológica. Tal redução não implica em uma remoção completa das camadas significantes que encobrem o objeto, o qual apareceria como realmente é. Fenômeno,

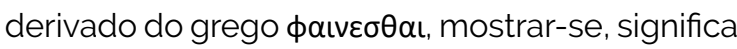
nesse contexto "aquilo que se mostra em si mesmo" (HEIDEGGER, 2006, p. 67). ${ }^{3}$ A redução consiste em uma atitude de olhar com espanto o mundo que cerca o observador. Nesse espanto duvida-se dos valores apriorísticos conferidos ao objeto. "A crítica do conhecimento quer antes elucidar, clarificar, ilustrar a essência do conhecimento e a pretensão de validade a que pertence à sua essência" (HUSSERL, 1986, p. 57). Assim, ao mesmo tempo em que descrevemos os argumentos geopolíticos sobre a Amazônia, colocamos em suspensão os pressupostos nos quais aqueles argumentos se apoiam, tratando os pressupostos como fenômenos, para além de suas manifestações. A hipótese que norteia esse artigo é que a análise geopolítica é um espelho. Informa sobre o objeto, na mesma medida que informa também sobre intenções do analista.

O termo geopolitica foi cunhado em uma obra

\footnotetext{
2 Por ideologia entendemos, ao nivel conceitual mais básico, a formulação de Karl Marx e Friedrich Engels: um discurso que tenta mascarar, naturalizar ou justificar relações de dominação. Segundo Marx, se os dominados percebessem a dominação como realmente é, uma violência, se rebelariam imediatamente. Devemos observar também, que a ideologia não é criada propositadamente. Ela habita as ficções simbólicas que regulam a realidade. Assim, seguindo esta assertiva, a metáfora 'véu da ideologia' torna-se inadequada, pois, ao contrário de ser algo que turva a visão de realidade, a ideologia insere-se nas estruturas narrativas da realidade enquanto tal. Maiores detalhes, ver: Freeden (2008), Mészáros (2004) e Žižek (1996).

3 Heidegger, no entanto, não deixa de reconhecer outros significados possíveis de фaıvó $\mu \varepsilon v$ vov como aparência, parecer e aparecer. Com a intenção de não inviabilizar o método fenomenológico, ele executa essa distinção precisa. Essas três palavras designam modificações privativas de um fenômeno. Assim, ele as remete ao conceito de manifestação. "[M]anifestação enquanto manifestação de alguma coisa não significa mostrar-se a si mesmo, mas um anunciar-se de algo que não se mostra através de algo que se mostra. Manifestar-se é um não mostrar-se" (HEIDEGGER, 2006, p. 68). O manifestar-se de algo pode ser apenas um índice visivel, envolto por um sintoma, enquanto a coisa - ou o ente - permanece encoberta. Fenômeno, mostrar-se em si mesmo, significa um modo privilegiado de encontro. Manifestação, ao contrário, indica no próprio ente uma remissão referencial, de tal maneira que o referente (o que anuncia) só pode satisfazer a sua possivel função de referência se for um 'fenômeno', ou seja, caso se mostre em si mesmo. Manifestação e aparência se fundam de maneira diferente, no fenômeno. Essa multiplicidade confusa dos "fenômenos" que se apresenta nas palavras fenômeno, aparência, aparecer, parecer, manifestação, mera manifestação, só pode deixar de nos confundir quando se tiver compreendido, desde o princípio, o conceito de fenômeno: o que se mostra em si mesmo" (HEIDEGGER, 2006, p. 70, grifo nosso).
} 
de 1916, O Estado como forma de vida, escrita pelo sociólogo sueco Rodolf Kjellén, ligando o estudo das relações entre o território e habitantes, sob a estrutura do Estado (CASTRO, 1999, p. 2223: MEIRA MATTOS, 2011a, p. 85). Assim Kjellén filiava-se aos estudos do geógrafo alemão Friedrich Ratzel, o qual desde a obra Geografia politica de 1903, avançava na direção de avaliar cientificamente as possibilidades políticas de um Estado diante da situação geográfica. Ratzel e Kjellén tentaram desenvolver tais estudos de acordo com a ótica científica. Isso implica, grosso modo, em analisar as fontes com métodos rigorosos; coletar dados sob os mais diversos aspectos representativos do objeto e enunciar leis a partir daquela observação sistemática. Tais leis deveriam explicar os fenômenos e ainda fazerem previsões. Conforme o general Meira Mattos:

Partiram ambos não da pesquisa abstrata do que devem ser os Estados, mas da observação concreta do que são os Estados. Esse modo de analisar o fenômeno estatal é processo rigorosamente científico do modo usado pelas ciências físicas, naturais e sociais, numa palavra, pelas ciências de observação. É a aplicação do processo indutivo experimental iniciado por Bacon e Galileu (MEIRA MATTOS, 2011a, p. 86, grifo nosso).

Em suma, o discurso empregado utiliza ou remete insistentemente a termos como rigor, realidade ou metódico, partindo assim do pressuposto que o conhecimento científico - nos moldes preconizados no século XIX - produziria um saber positivo e válido. ${ }^{4}$

O descrédito sofrido pela geopolítica seria, segundo alguns autores aqui citados - Meira Mattos (2011a), Terezinha de Castro (1999) e Bertha Becker (2009a) -, derivação direta da apropriação da mesma pelos nazistas. O general alemão Karl Haushofer, no
Instituto de Geopolítica de Munique, teria direcionado os estudos daquele centro para justificar a política expansionista de Adolf Hitler, formulando doutrinas agressivas de expansão territorial. Contudo, o nazismo seria apenas o exemplar extremo. Cabe observar que o surgimento da geopolítica, na primeira metade do século $X X$, coincidiu com uma profunda reformulação dos sistemas de poder mundiais, marcado pelas duas grandes guerras e a Revolução Russa. Os movimentos expansionistas territoriais no período foram ditados por avaliações ou mesmo por projeções geopolíticas, ou pelo menos que apareciam como tal. Cite-se a tentativa de criação da Grande Sérvia nas Guerras Balcânicas de 1912-1913, o revanchismo francês focado na reconquista da Alsácia Lorena, o próprio Lebensraum nazista ou mesmo o expansionismo territorial russo mantido na União Soviética revolucionária. O objetivo da geopolítica seria apenas justificar manifestações de poder estatal?

As próprias concepções da disciplina, mesmo nas vertentes mais rigorosas, partiam de axiomas como o "povo, entidade viva". Johann Gottfried von Herder (século XVIII), enxergava o povo (Volk) passando necessariamente pelos estágios biológicos de nascimento, crescimento e maturação. O Estado representaria a organização ideal e desejável de um determinado povo. Para Immanuel Kant e Friedrich Hegel, o Estado ideal seria a realização suprema da história humana, assegurada pela Natureza. Assim chegamos ao conceito de 'nação', ressignificado durante o curso da Revolução Francesa: um povo que coabita um território, partilhando língua e cultura comuns, com base sentimental. Presentes no mesmo campo semântico, povo e nação, contam uma narrativa onde terra e habitantes nascem e desenvolvem-se naturalmente, precedendo

4 Cabe aqui chamar a atenção para dois aspectos fundamentais. O primeiro é epistemológico, recaindo justamente nos limites do conhecimento positivo derivado do método empírico. Conforme Bertrand Russell e Thomas Kuhn, o método empírico não revela a "verdade". Tal procedimento tão somente indica o possivel, e não o certo. Kuhn (1997) também demonstra que a observação é precedida pela teoria e não ao contrário, como desejavam os cientificistas dos Oitocentos. O olhar é condicionado pela teoria (do verbo grego $\theta \varepsilon \omega \rho \varepsilon \dot{\omega}$, 0 qual apresenta como um dos sentidos observar aquilo que se mostra) e a mesma direciona o conhecimento produzido. $O$ segundo aspecto é ontológico. Ao tentar construir os logói das humanidades, buscando emular a exatidão e a verdade das ciências da natureza (ainda a partir dos Oitocentos), parte-se do axioma segundo o qual a condição humana pode ser comparada a elementos químicos, no tocante à previsibilidade das reações. Nesse sentido, seria mais adequado narrar os eventos humanos em função de condicionantes e desdobramentos, ao invés de causas e consequências. Uma causa implica obrigatória e necessariamente em uma consequência especifica. Já os condicionantes e desdobramentos abarcam com mais propriedade as vicissitudes da condição humana. Nas palavras de Mark Bevir, "A explicação condicional define-se em oposição à explicação causal como forma apropriada ao ato racional. Aparece nos casos em que uma coisa não precisa de outra, apenas fornece a alguém motivo para agir de um modo que acarrete essa outra" (2008, p. 27, grifo nosso). 
o Estado, o qual, bem organizado, conduzirá a população e o território amalgamados na nação ao destino merecido e justo. Seria, segundo a mesma exposição já referenciada de Kant, o plano da Providência Divina, expressa na Natureza. ${ }^{5}$

$\mathrm{Se}$ a narrativa ideológica mostra um desenvolvimento natural até o Estado, historicamente o desenvolvimento foi o inverso. Estados criam nações e não o contrário. Território, lingua, povo e tradição não podem ser critérios objetivos para a existência de uma nação pelo simples fato de não serem dados puros, presentes na realidade por si só e auferidos pelo ser através da simples observação. Territórios e fronteiras apresentam muitas variações, no tocante à duração. Enquanto as fronteiras do continente americano apresentaram poucas e pontuais mudanças nos últimos duzentos anos, a Europa mudou bastante as linhas fronteiriças nas últimas três décadas, e muito mais desde o século XIX. O Brasil, a título de exemplo, perdeu a província Cisplatina (atual Uruguai), incorporou o território (hoje estado) do Acre e avançou para o oeste a fronteira com o Paraguai, após a guerra de 18641870. Já o continente europeu, desde 1988, assistiu paises desaparecerem, surgirem, ressurgirem e fundirem-se: Alemanha Ocidental e Oriental, União Soviética, Ucrânia, lugoslávia, Tchecoslováquia, Letônia, Lituânia, apenas para citar alguns.

As línguas nacionais também não surgem de maneira natural. É um fato aceito que a lingua falada se reinventa cotidianamente, através dos praticantes. Contudo, há um abismo entre a língua falada e a língua nacional, determinada através das regras gramaticais. É uma construção deliberada, e disseminada, por entre diversos polos, pelo sistema de ensino de qualquer pais.
Tal constructo serve, não de modo secundário, a uma base ideológica de reafirmação da cultura nacional. O papel ideológico da escola, nesse contexto, é fundamental. A escola ensina a lingua nacional, a literatura nacional, a cultura nacional, a história nacional e a geografia nacional. Lingua, povo, território. Essa tríade envolve as tradições da nação. Devemos observar também que a ideia nacional é uma via de mão dupla. O esforço vertical na construção daquela ideia não significaria nada, sem haver recepção por parte do corpo civico. Obviamente, tal recepção não opera de modo cartesiano. Na feliz expressão de Benedict Anderson, uma nação é uma comunidade imaginada, um constructo social, envolvente e que confere sentido à população local (2008).

Os estudiosos dividem as primeiras escolas geopoliticas em duas vertentes: a Determinista (alemã) e a Possibilista (francesa) (CASTRO, 1999, p. 25: MEIRA MATTOS, 2011a, p. 85-88). A primeira defendia a assertiva que a geografia determinava o destino dos povos; a segunda indicava a geografia como indicativo de soluções favoráveis ao destino dos povos. A assim chamada escola possibilista - diante do exposto na bibliografia disponivel em língua portuguesa - quer parecer mais uma categoria ex post do que realmente uma escola. Sobre o principal nome dessa vertente foi afirmado que o mesmo quase alcançou a geopolitica: "Embora apoiado na História, o ponto de vista geográfico domina o trabalho de Vidal de la Blache que, certamente, teria chegado à Geopolítica" (CASTRO, 1999, p. 26). Quase, por pouco, um mero imprevisto: o acaso impediu que la Blache atingisse o alvo determinado. Se ele é o principal representante, como pode o possibilismo ser uma escola? ${ }^{6}$ Talvez o assim nomeado possibilismo

\footnotetext{
5 Os conceitos de natureza, emergentes a partir dos séculos XVI e XVII, remeteriam - grosso modo - ao mecanismo criado pela divindade. Partindo da ideia de um deus relojoeiro, o qual montou um mecanismo e o deixou funcionando, tornou-se um topos a concepção todo o universo estaria ordenado, funcionando como um mecanismo. Bastaria, portanto, descrever a lógica - através da ciência - de tal mecanismo para apreender não apenas a realidade que nos cerca, como também o papel dos seres humanos, e das nações - no mesmo cosmo. Dai a preocupação de vários pensadores do período em formular leis e direitos naturais, a título de exemplo.

6 Quer nos parecer que ocorre, nesse didatismo, um mecanismo semelhante ao enquadramento histórico do socialismo (século XIX) e da nascente teoria das Relações Internacionais (século XX). A divisão entre socialistas científicos e utópicos foi criada por Marx e Engels objetivando desqualificar os adversários. Como estes se autoproclamavam científicos, o socialismo proposto seria, portanto, preciso, exato e verdadeiro. Os utópicos (os demais) seriam apartados da realidade da vida, buscando um mundo ideal. Já na teoria das Relações Internacionais, está bem estabelecido que o Idealismo foi inventado por Edward Carr (2001) para reforçar as próprias posições epistemológicas. A própria nomenclatura indica com clareza: realistas enxergam o objeto como realmente é; idealistas buscam arquétipos platônicos. O fato de existirem autores assumidamente realistas (Carr e Morgenthau na primeira geração) e não existir nenhum idealista autointitulado reforça nossa tese. No tocante à geopolítica, tal disposição de pensadores sugere que a escola possibilista, em oposição à determinista, foi nomeada para fornecer uma impressão de correntes diversificadas de pensamento. Afinal, a postura possibilista aparece mais como uma negação: seria uma postura não determinista.
} 
seja, no máximo, uma reunião de posições que não condizem com o determinismo.

Já o determinismo teutônico encontra uma guarida mais sólida e, inclusive, descrição mais extensa na bibliografia. Os grandes nomes dessa escola são justamente os fundadores do pensamento geopolítico: Ratzel e Kjellén. Ambos buscaram exemplos históricos sobre a formação, expansão e queda dos grandes impérios. Assim poderiam derivar leis aplicáveis aos Estados contemporâneos. Na Geografia politica, Ratzel avança na concepção corpórea, concebendo os Estados como organismos biológicos, em um raciocinio semelhante ao de Herder. Assim, ele concebeu leis acerca do crescimento do Estado, leis que se baseavam na concepção de espaço vital (Lebensraum), o qual posteriormente foi apropriado por Hitler em Mein Kampf (2005). O Estado, portanto, para Ratzel, cresceria como um organismo vivo, alimentando-se dos espaços vizinhos, sustentandose nas variáveis povo e território (CASTRO, 1999, p. 28). A sexta lei é reveladora quando afirma que o motor para o crescimento territorial é a superioridade de uma civilização sobre outra. A terra moldaria o povo e povo se imporia através do Estado. Ao Estado caberia indicar as direções a serem seguidas. Tais concepções derivam, também, de uma visão nacionalista.

Meira Mattos indica uma terceira via de posicionamento: desafio e resposta, derivada dos escritos do historiador inglês Arnold Toynbee. Seria um meio termo das posições determinista e possibilista: seriam vitoriosas as nações que sobrepujaram os desafios do meio geográfico e "de suas próprias contradições psicossociais" (MEIRA MATTOS, 2011a, p. 88), e fracassadas as que obviamente não conseguiram. De acordo com um posicionamento positivista, esse seria um meio termo e, literalmente, um meio termo que não se compromete, ao formular critérios vagos de "sucesso" e "fracasso". Deduz-se que a linha divisória entre ambos conceitos seja, no minimo, a sobrevivência do corpo político no tempo, incluindo aí a manutenção do território, soberania e interesses estatais. Não oferecendo variáveis bem definidas, tal assertiva não poderia ser considerada uma "lei cientifica". No entanto, os fenômenos humanos não poderiam ser descritos conforme as ciências naturais. Meira Mattos finaliza a sintese das escolas geopoliticas com três frases reveladoras: a "geopolítica é a consciência geográfica do Estado [Ratzel]", "espaço é poder [Ratzel]" e ele finaliza a passagem adicionando também "geografia é destino" (MEIRA MATTOS, 2011a, p. 88).

Tais frases são reveladoras, pois já conduzem o leitor para o raciocinio original do autor. Meira Mattos concebe o 'sucesso' como a conjunção feliz dos homens com o meio natural, a qual geraria "sociedades progressistas" (MEIRA MATTOS, 2011a, p. 90) ao longo da história humana. O homem ai citado é o coletivo, o povo. Tomando como um axioma a assertiva de Toynbee, sobre a facilidade ser inimiga da civilização, o autor discorre sobre como dificuldades impostas sobre os mais diversos povos tornaram-se os motores para o desenvolvimento dos mesmos. As facilidades do meio terminariam - seguindo esse raciocinio - criando uma raça de indolentes. Dificuldades extremas, por outro lado, poderiam superar a capacidade de superação dos habitantes da região. Sendo assim, o meio áspero (mas nem tanto) seria essencial para a forja da nação: "caberá ao homem responder a esses desafios [do meio]. Ou responde e os supera, ou não responde e é derrotado" (MEIRA MATTOS, 2011a, p. 94).

Há duas variáveis então: meio (natural) e o povo. O meio oferece obstáculos, contudo tais barreiras devem se apresentar na exata medida aristotélica (tón mesón): nem irrisórios, nem impossiveis. O povo se desenvolve ou não respondendo de alguma forma aos estímulos do meio. O território, portanto, é mostrado como um todo absoluto (sendo parte da natureza, o território seria neutro no tocante à distribuição de benesses ou dificuldades, como a Roda da Fortuna medieval), o qual executa um juizo quase divino. Essa ou aquela terra testará o povo, e o povo que se mostrar capaz, receberá o grande prêmio. Tal narração sugere uma espécie de eleição divina de um povo escolhido. Um dos mitos fundadores dos Estados Unidos justamente 
versa sobre a excepcionalidade americana7 e o destino manifesto. Pode-se perceber tal mitema na formulação de Sérgio Buarque de Holanda em Raizes do Brasil: diante do fracasso da colonização holandesa do Nordeste brasileiro, tornou-se claro - uma observação empírica para Holanda -, que somente os portugueses estavam habilitados a colonizar este pedaço do mundo.

Devemos observar, também, o caráter teleológico dos termos utilizados, território e povo. O duplo envolvimento, povo ocupando território, território acolhendo (e testando) o povo, enseja uma prefiguração de ambos. Os dois são apresentados - ao menos no nível superficial como consolidados e monolíticos, sem um devir. Assim como a historiografia tradicional brasileira que narra de Brasil e povo brasileiro existentes desde o século $\mathrm{XVI},{ }^{8}$ tal concepção assenta-se em entidades prontas e acabadas. Logo, há que se levar em consideração, também, os acréscimos e decréscimos territoriais; as migrações externas e internas e os pactos políticos (ou mesmo a inexistência deles) na formação de qualquer Estado.

O território é analisado, sob o olhar de Meira Mattos, em três aspectos: a forma, as fronteiras e a posição. Assim, "com base nos vetores espaço, posição e fronteiras, haveriam de firmar o poder nacional e projetar o país [Brasil] no cenário regional e global como grande potência" (CERVO, 2008, p. 120). As formas podem facilitar ou prejudicar a coesão interna e a defesa de um território. Os tipos alongado, recortado e fragmentado podem suscitar os mais variados obstáculos relativos à unidade territorial. Já a formação compacta, onde as fronteiras sofrem ação centrípeta, é a mais adequada para a manutenção da unidade territorial.

Fronteira pode ser definida inicialmente como "uma linha de demarcação traçada entre dois bens imóveis onde se queira evitar o surgimento de controvérsias" (ZIENTARA, 1989, p. 307). Sob a visão da politica internacional seria a separação entre duas soberanias. As origens linguísticas do conceito fronteira remonta a algumas linguas indo europeias: Bhruva (sânscrito), synoro (grego) ou frontem (latim). O conceito refere-se à oposição entre dois territórios. Semanticamente, a frente situa-se diante de algo. O mundo civilizado diante da barbárie. Nós diante deles. A frente também pode ser pensada como um confim territorial. A margem que delimita (palavra derivada do latim limes) dois mundos ou, pelo menos, duas entidades soberanas distintas. As marcas carolíngias agiam no sentido defensivo, servindo como região espessa de contenção das incursões bárbaras. 0 limes servia tanto para defesa do mundo romano, quanto para plataforma de expansão territorial. Na modernidade, concebeu-se a ideia de Estados tampões, os quais interpostos entre potências, amortizam o choque fronteiriço entre elas.

Friedrich Ratzel definia a fronteira como um conjunto de "inumeráveis pontos sobre os quais um movimento orgânico é obrigado a parar" (RATZEL, 1899 apud ZIENTARA, 1989, p. 306). Nesse sentido, é concebida como uma marco flutuante e também como uma via de mão dupla. Tanto pode ser a linha de contenção de ameaças externas, quanto o ponto de partida para expansões. Karl Haushofer foi mais além, narrando uma tipologia agressiva das fronteiras, as quais não deviam respeitar nem o direito internacional, nem acidentes geográficos. Deveriam levar em consideração apenas a "paisagem cultural", termo vago o suficiente para ser preenchido por incontáveis significados. A classificação e gradação das fronteiras, então, seguiria a seguinte

\footnotetext{
7 Deve ser observada aqui uma sinédoque, a qual reflete não apenas uma questão conceitual, mas também uma questão imagética Naturalmente conceito e imagem estão ligados no campo semântico político. Os Estados Unidos da América são normalmente nomeados como América ou América do Norte. Referindo-se ao território e habitantes como América do Norte e norte-americanos, ocorre uma obliteração do México e Canadá. Estes seriam anexos sem importância. Ao se grafar e falar América e americanos com aquele sentido. os contra conceitos respectivos seriam América Latina e latino americanos, os quais não são, e não pertencem à verdadeira América.

8 No atual debate historiográfico, concebe-se que o Brasil não foi "descoberto" por Pedro Álvares Cabral ou por qualquer outro explorador O Brasil seria uma invenção da historiografia do século XIX. Obviamente temos consciência que o nome 'Brasil' já era associado à América Portuguesa desde 1503, pelo menos. Contudo esse Brasil seria a nomeação do conjunto de encraves coloniais lusitanos na América e não um conjunto coeso e linear. Segundo Maria Odila da Silva Leite Dias, o processo de "interiorização da metrópole" só teve início em 1808 . com a transferência da Corte para o Rio de Janeiro. Desse modo, o centro administrativo da América Portuguesa construiu linhas de comunicação e autoridade com os demais recônditos da ex-colônia. Naturalmente tal processo foi lento e gradual. No mínimo durou até 1850.
} 
ordem: $\alpha$ ) ataque; $\beta$ ) manobra; $\gamma$ ) equilibrio; $\delta$ ) defesa; $\varepsilon$ ) decadência e $\zeta$ ) apatia (MEIRA MATTOS, 2011a, p. 108). A ordem e a nomenclatura utilizadas demonstram bem como deve ser uma atitude correta em relação às fronteiras, segundo o pensamento extremista (pseudogeopolítico, segundo Meira Mattos) de Haushofer.

Meira Mattos oferece uma sintese das posições organicistas (por contraste, eliminou-se Haushofer como exemplo do que não deveria ser feito) e do bom senso, chegando à concepção da fronteira como uma região sensivel das ações estatais. Sendo assim, o cuidado dispensado pelo Estado refletirá em fronteiras estáveis ou não, impedindo ou estimulando tensões (MEIRA MATTOS, 2011C, p. 34). A fronteira, por outro lado, também pode ser enquadrada como um mundo à parte, dotada de regras e dinâmicas próprias.

[A]s populações que vivem numa zona de fronteira dão origem a uma comunidade fundada em interesses particulares, mantêm entre elas, do lado de cá e do lado de lá da fronteira, uma intensa comunicação [...]. Estes habitantes das zonas de fronteira consideram-se um grupo à parte que se opõe a ambas autoridades estatais (ZIENTARA, 1989, p. 309).

Tais dinâmicas podem - se nos permitirmos aqui uma metáfora mecânica - servir como motores de atração ou repulsão dos centros administrativos dos entes soberanos. Portanto, um estudo detalhado dessas dinâmicas nas regiões especificas, também é necessário. Como os habitantes fronteiriços se veem? Como eles veem o centro administrativo do Estado? Como eles veem os habitantes do outro lado do limes?

A posição remete aos obstáculos naturais ou à inexistência deles. Os obstáculos são subdivididos em quatro partes: latitude (tropical ou temperado); proximidade do mar (maritimo ou continental); posição em relação aos vizinhos; e altitude (montanhas, planaltos, planícies, vales etc.) (MEIRA MATTOS, 2011c, p. 100-104). Os territórios podem ser reagrupados em três categorias, conforme a predominância dos elementos: $\alpha$ ) marítimos; ß) continentais; ү) mistos. A conjunção desses fatores indica, sugere, conduz à proposições e soluções estratégicas para o Homem de Estado.

As ações de defesa, preocupação permanente de qualquer Estado, são planejadas seriamente a partir desses fatores. Conforme a percepção acerca do tipo de território, somados a fatores conjunturais (politicos, econômicos, dentre outros), a defesa nacional é concebida. Os formuladores da política estatal vivem, nesse sentido, no futuro. Tentando antecipar tendências e problemas vindouros, percebem e projetam essas questões - em uma perspectiva geopolítica, tomando a mesma como guia - e planejam ações de modo prudente. A prudência aqui é enquadrada no sentido clássico empregado por Marco Túlio Cícero e, posteriormente, por Nicolau Maquiavel: o agir correto no momento oportuno. O homem prudente projeta vários cursos de ação para situações hipotéticas igualmente diversas (ARGUELHES, 2013, p. 358). Deste modo, fica preparado para atingir objetivos propostos ou para proteger interesses. No caso do Homem de Estado, sendo a defesa nacional a principal preocupação, a percepção de ameaças ao território, fronteiras, soberania e interesses devem merecer atenção especial.

Tais apontamentos permitem um paralelo conveniente com as teorizações de Pierre Renouvin e Jean-Baptiste Duroselle acerca da interação do Homem de Estado com as forças profundas na formulação dos interesses nacionais (1967, p. 333). O interesse nacional, diverso do interesse do príncipe, é formulado, em última instância, pelo Homem de Estado. Nesse processo o governante sofre pressões, ao mesmo tempo que tenta moldar, as forças profundas. O território seria uma parte integrante das forças profundas (as quais incluem também as conjunturas políticas e econômicas; pressões da opinião pública e demográficas). A percepção sobre o território, aliado aos outros quesitos, influem na escolha dos objetivos nacionais, juntamente com o cálculo e planejamento necessários para alcançar as metas propostas. Oportunidades e ameaças são percebidas e incluidas no planejamento.

Finalmente chegamos a um ponto essencial para o prosseguimento do texto, após a colocação dos 
elementos iniciais. O espaço geográfico territorial não pode ser um grande demiurgo, apreendido objetivamente de forma invariável através dos tempos. Ao menos duas questões podem ser colocadas: como o território é percebido? Como essa percepção é representada? Se concebemos o território como um aspecto perene (só variando de acordo com movimentações da linha de fronteira) dos elementos que integram o cálculo sobre a defesa nacional, aqueles questionamentos não podem ser ignorados. Até mesmo a representação pictórica de um território - um mapa - jamais poderá ser considerada 'neutra', conforme já citado anteriormente, na epigrafe retirada dos escritos de Borges.

Literalmente, os mapas "não se fazem", mas são feitos por alguém. Atrás dos pontos, linhas e poligonos impressos no papel escondem-se homens (e mulheres) e suas razões, ações e contradições cartográficas que influenciam ou até determinam como devem ser a aparência e os conteúdos de um mapa. Mapas são textos culturais, e não espelhos do mundo, embora eles ajudem a fabricar essas realidades (SEEMANN, 2012, p. 69, grifo nosso).

Não se pode perder de vista que a mimesis é uma filtragem dupla: percepção acrescida da narração. A narração não precisa ser necessariamente expressa em palavras impressas, pode ser em imagens. O mapa é também um texto a ser lido.

\section{Longe dos olhos: Brasil e Amazônia}

O território é, portanto, uma constante tradução de percepções em signos. Meira Mattos descreve tipos de território no tocante à forma e à posição, conforme indicamos acima. Ambos seriam condicionantes das projeções geopoliticas. Se há filtragens entre o ambiente e a análise geopolítica, então o olhar deitado sobre o objeto torna-se um caminho de mão dupla. $O$ objeto impressiona a retina e a retina enxerga o objeto através das lentes teóricas e de preceitos políticos, epistemológicos e ideológicos.

O espaço "puro" do geógrafo não é o espaço abstrato do geômetra: é o azul do céu, fronteira entre o visivel e o invisivel; é o vazio do deserto, espaço para a morte [...]. Esse espaço material não é, de forma alguma, uma "coisa" indiferente, fechado sobre ele mesmo, que se dispõe ou que se pode descartar. É sempre uma matéria que acothe ou ameaça a liberdade humana. Uma região montanhosa não é, antes de tudo, uma região que obstrui a circulação dos homens? A planície só é "vasta", a montanha só é "alta", a partir da escala humana, à medida dos seus desígnios. A floresta é experimentada como "espessa", a Amazônia sentida como "quente", antes que essas qualidades sejam conceituadas em noções aprendidas. [...] Fora de uma presença humana atual ou imaginada, não há nem mesmo a geografia física, somente uma ciência vã. O antropocentrismo não é uma imperfeição, mas uma exigência inelutável (DARDEL, 2011, p. 8).

Obstáculos ou passagens tornam-se, desse modo, medidos pelo olhar humano. A distância entre a cidades do Rio de Janeiro e Corumbá, no atual Mato Grosso do Sul, podia ser medida em vários dias de viagem, em meados do século XIX. Hoje significam poucas horas de voo. Desertos vazios podem ser cultivados, montanhas podem ser abertas por estradas e tuneis. Na Europa de 1940, onde ingleses e franceses enxergaram uma barreira intransponivel para a Blitzkrieg da Wehrmacht, o general alemão von Manstein percebeu um atalho para a vitória. Era a Floresta das Ardenas. Ao se modificar o olhar, o objeto transforma-se. Além disso, é o olhar do analista que confere sentido ao observado. O olhar deitado sobre o objeto é uma via de mão dupla. A análise geopolítica revela muito ao ser humano, na mesma medida que revela algo também sobre os seres humanos que a formularam.

A região amazônica, floresta tropical que circunda a bacia do rio de mesmo nome, é conhecida desde o século $\mathrm{XVI}$. O relato mais famoso é justamente o dos viajantes espanhóis Gaspar de Carvajal e Francisco de Orellana, elaborado após a exploração do rio entre 1539 e 1542. Nos dois primeiros tratados de limites entre as Américas Portuguesa e Castelhana (1493 e 1494), a região localizava-se inteiramente no território do segundo. Após o princípio da União Ibérica (1580-1640), os colonos portugueses avançaram além dos limites das Tordesilhas, já 
que este acordo havia perdido a validade. Nas tratativas de Madrid (1750) e Santo Idelfonso (1777), a região amazônica já aparecia, na maior parte, dentro das fronteiras lusitanas. Os acordos de limites assinados pelo Brasil entre o século XIX e meados do século XX confirmavam o território amazônico outrora de Portugal como brasileiro, e ainda acrescentou-se o atual estado do Acre, por força do Tratado de Petrópolis (1906).

Panamazônia foi um termo cunhado pelo naturalista dos séculos XVIII e XIX, Alexander von Humbolt, justamente significando o espaço da floresta que abarcava ambos os lados da fronteira. Sobre o espaço amazônico, escreve o general Meira Mattos:

As palavras amazônia e pan-amazônia deveriam simbolizar a mesma imagem geográfica. Na realidade isso não acontece. Essa imensa região natural, portadora de ecologia uniforme, abrangendo o território de seis países tributários, é enfocada por seus condôminos sob uma visão particularizada. Assim é que quando o brasileiro ou venezuelano, colombiano, peruano, equatoriano ou boliviano refere-se à Amazônia está falando na sua Amazônia nacional (MEIRA MATTOS, 2011b, p. 17, grifo nosso).

A observação de tal economia linguística é deveras interessante. Cada nativo, em seu respectivo país, pensa em uma Amazônia própria, derivando qualquer outra com adjetivos. $O$ primeiro conceito sempre é o local. Os demais surgem como contraposições ou complementos.

O centro da exposição dessa sessão é o enquadramento geopolítico da Panamazônia, de acordo com o pensamento do general Meira Mattos. Em um escrito de 1980, ele abordou essa questão: Uma geopolitica pan-amazônica (MEIRA MATTOS, 2011b, p. 13-214). Retomando as considerações já feitas, unindo Kjellén, Ratzel e Toynbee, Mattos parte do conceito de geopolitica como aplicação da política aos espaços geográficos (MEIRA MATTOS, 2011b, p. 155). Ele afirma que tal enunciação não é simplória. Intuitivamente, o general busca um contra conceito, para delinear os limites do conceito dado, naquilo que ele denomina o comparativo dos contrários. "O que seria uma antigeopolítica?" (MEIRA MATTOS, 2011b, p. 155). Seria simplesmente uma ação política (nesse sentido entendido no âmbito estatal) ignorando os espaços geográficos onde devem ser aplicadas. Um exemplo simplório disso seria a aplicação da mesma política pública no Rio Grande do Sul, Piauí e Acre, desconsiderando qualquer particularidade climática, populacional ou econômica próprias das regiões afetadas.

Portanto, qualquer ação do Estado brasileiro com vistas à ocupação, ao desenvolvimento, à integração ao restante do território, tem que levar em conta uma profunda análise geopolítica, baseada em critérios como natureza, clima, extensão, posição e população (MEIRA MATTOS, 2011b, p. 155). O potencial da região é grandioso, gerando simultaneamente oportunidades e potencialidades, fraquezas e ameaças. As oportunidades e potencialidades residem nos recursos regionais (do potencial hidráulico aos recursos minerais, passando pela fauna e flora). As fraquezas e ameaças advém da ainda não integração efetiva ao restante do território brasileiro e à cobiça internacional. Desde meados do século XIX o governo brasileiro percebe - e manobra contra - várias ameaças extra fronteiriças. Um diplomata estadunidense observou certa vez que a menção à palavra Amazônia por qualquer estrangeiro deixava os brasileiros nervosos. Tal observação também pode funcionar para o outro lado: uma Amazônia brasileira pode ferir suscetibilidades.

Qual seria, em sintese apertada, um caminho apontado por Meira Mattos para defender a Amazônia? Seria a cooperação com os condôminos da Panamazônia. O Tratado de Cooperação Amazônica, assinado em 1978, congrega os países que compõe a região e abre caminho para soluções compartilhadas. O texto do tratado apresenta uma disposição deveras interessante. O preâmbulo do tratado é apresentado em uma perspectiva de extrema união entre os países integrantes. Um acordo internacional, ao menos teoricamente, depende da vontade comum. Tal espirito é indicado naquela parte, ao destacar as palavras iniciais de cada parágrafo: "Conscientes [...], Animadas [...], Convencidas [...], Considerando [...], Cônscias [...], Seguras [...], Persuadidas" (OTCA, 2013). O texto conduz à harmonia que deve (ou 
pelo menos deveria) reinar entre as partes. Em 1998, para reforçar, ou mesmo para tentar conferir alguma dinâmica, foi fundada a Organização do Tratado de Cooperação Amazônica. A iniciativa para maior integração da região continuou no campo diplomático, com resultados muito limitados, para dizer o mínimo.

Meira Mattos continua o raciocínio expondo o problema da continentalidade ${ }^{9}$ do Brasil, em particular da Amazônia. Utilizando a comparação com a Rússia, Estados Unidos e Austrália, Meira Mattos busca modelos do que deve e do que não deve ser feito. Os Estados Unidos, durante a implacável Marcha para o Oeste, ao longo dos Oitocentos, incorporou a imensa massa continental do Meio Oeste por através de ferrovias. Essas ligaram as duas costas (Leste e Oeste), enquanto o Mississipi integrava o Norte e o Sul. Rússia e Austrália servem de contraponto para o modelo estadunidense (MEIRA MATTOS, 2011b, p. 159-164). Qual seria esse modelo? Sem dúvida nenhuma corroborando a própria definição de geopolítica do autor -, seria justamente a utilização das vantagens geográficas (o rio Mississipi) e o contorno das desvantagens (a construção da malha ferroviária). Tudo organizado e direcionado pelo Estado, buscando a integração e desenvolvimento.

Esse duplo objetivo aplicado à Amazônia e à Panamazônia fica bem claro na seguinte passagem:

No Brasil de hoje, o cerne do problema do despertar da continentalidade está centrado na Amazônia, uma vez que nas regiões interiores mais próximas do Sudeste e de Brasilia a questão da expansão da fronteira econômica se encaminha naturalmente e não deverá exigir soluções estimuladoras mais fortes. A integração dos nossos 5 milhões de km2 [amazônicos], somados aos 2 milhões de $\mathrm{km}^{2}$ dos nossos vizinhos, hoje ligados a nós pelo Tratado de Cooperação, é que irá exigir maior esforço.

Integrar a Pan-Amazônia será obra hercúlea, de leal cooperação, a ser impulsionada desde já. [...] [S]erá preciso montar-se uma estratégia adequada e própria, que responda aos objetivos pretendidos e às peculiaridades regionais (MEIRA MATTOS, 2011b, p. 164-165, grifo nosso).

Não apenas a integração da região amazônica ao Brasil, mas também a integração de toda Panamazônia, ou seja, a integração das demais Amazônias aos respectivos países e a integração de todas elas no espaço do Tratado. Quais seriam os desdobramentos de tal movimento geopolítico? O primeiro seria a transformação da Panamazônia em uma hinterlândia dos condôminos. Grosso modo, seria o deslocamento de uma área fronteiriça - a qual sempre atraiu a cobiça internacional -, para uma região cercada pelos signatários da OTCA, minimizando a área a ser protegida de uma eventual ameaça à segurança da região. A primeira linha de defesa da Amazônia - neste contexto - é o bloco da OTCA.

Obviamente o Estado brasileiro não pode confiar toda a defesa da região amazônica àquele bloco, sob pena de poder se encontrar constrangido por elementos alheios à vontade nacional. A OTCA deve ser a primeira, mas não única linha de defesa. Uma integração responsável e bem planejada - conforme descrita em Uma geopolitica pan-amazônica (MEIRA MATTOS, 2011b, p. 11-214), de Meira Mattos -, capaz de desenvolver e integrar a região (entre os centros dos respectivos países e entre si), consolidaria a segurança local. Tal iniciativa também minimizaria o que Meira Mattos denomina como o Imperialismo brasileño. ${ }^{10} \mathrm{O}$ temor dos nossos vizinhos acerca de

\footnotetext{
9 Continentalidade e maritimidade são dois conceitos antitéticos na geopolítica. Estados podem ser exclusivamente de um ou de outro tipo, ou ainda mistos. A determinação de maior incidência de um ou de outro nos tipos mistos, é feita por operações matemáticas, dividindo-se a extensão da fronteira considerada pela extensão total das fronteiras. Nesses dois polos, considera-se que paises continentais tem maior dificuldade de expansão e projeção de poder e maiores ameaças à soberania, enquanto paises marítimos tem maior facilidade justamente naqueles pontos.

10 Meira Mattos, 2011b, p. 157. Ė o medo dos países vizinhos do protagonismo político brasileiro. Esse temor, na superfície, ligado ao tamanho desproporcional do Brasil em relação aos demais países da América do Sul (territorial, populacional e econômico, dentre outros). faz com que a atuação brasileira na região seja pautada pela cautela. Desde 1870 o Brasil nunca mais se envolveu como beligerante nas guerras do subcontinente, nem fez intervenções militares nos países vizinhos. Em um nivel abaixo, tal fator vira uma moeda política regional na politica interna dos nossos vizinhos. No próprio Paraguai, o tópos imperialismo brasileño é tido como um axioma. No caso da renegociação do acordo da Usina de Itaipu, entre os presidentes Luís Inácio Lula da Silva e Fernando Lugo, a imprensa favorável ao governo local louvou Lugo, o qual teria imposto o interesse paraguaio sobre as pretensões brasileiras. A imprensa de oposição, no entanto, afirmou que o Brasil mais uma vez tinha vitimado o Paraguai, com anuência de Lugo. Esse fator, por motivos óbvios, não pode limitar o protagonismo brasileiro. Contudo deve ser levado em conta sempre.
} 
nossos supostos apetites de potência regional. A integração não resolverá todos os problemas de segurança na região. No entanto, só trará vantagens se bem conduzida.

Em termos geopolíticos, como tal integração funcionaria? Partiremos da conhecida assertiva de Montesquieu, expressa no Espirito das leis, a qual serviu de base para muitas fórmulas geopolíticas: "os mares aproximam, as cadeias de montanhas afastam" (MONTESQUIEU, 1996 apud MEIRA MATTOS, 2011, p. 87). Tomando tal afirmação como um ponto de partida e o aplicando à América do Sul, podemos observar que a disposição dos países amazônicos justamente tal movimento: as fronteiras terrestres entre eles são constituidas por vazios demográficos, enquanto a projeção dos mesmos se faz na direção dos mares. Destes países, o único que não possui litoral é a Bolivia, decorrência direta da Guerra do Pacíico (1879-1883).

Tal conformação geográfica não auxilia a integração proposta pelos tratados de integração amazônica. Invocando o mesmo modelo narrado por Meira Mattos, de integração física da região oeste dos Estados Unidos, podemos afirmar que isso se torna uma questão de organização e direção politica, a qual buscaria compensar o que não é fornecido pela paisagem. O OTCA deveria, nessa linha de raciocinio, operar justamente como um centro de atração para os demais países amazônicos, ligando-os ao Brasil, conforme já desenvolvido anteriormente.

A iniciativa diplomática, pura e simples, não será o suficiente para avançar na cooperação amazônica. O deslocamento semântico operado há quinze anos (de Tratado para Organização do Tratado), tampouco representou avanços substanciais como um todo. Se, portanto, a diplomacia por si só não é o bastante, então a integração deverá se desenvolver sobre um eixo de transportes, comunicações e comércio entre os paises. Em linhas gerais, isso também já se encontrava presente na obra de Meira Mattos, conforme a citação acima. Integração da Amazônia ao Brasil e, partir daí, a integração dos paises amazônicos através da Panamazônia. Ao contrário de outros teóricos e outros Estados, as fronteiras amazônicas do Brasil não seriam pontos de avanço ou mesmo um ponto de parada (provisória!) de um movimento orgânico. Seriam um elemento de integração, desenvolvimento e segurança, ao agregar efetivamente a OTCA.

A integração da região amazônica ao restante do País é um processo que ainda está em curso. O processo de construção do Estado nacional brasileiro, operado em longo termo, entre $1822 \mathrm{e}$ 1930, partiu de um projeto político especifico: fazer coincidir o território nacional com o antigo território da América Portuguesa. A posse e ocupação do território obedeceu a um critério geopolítico empírico, com o governo brasileiro reforçando a ocupação em pontos estratégicos defensivos, e também a critérios econômicos, naquilo que Bertha Becker denomina 'economia de fronteira'. Tal atividade se assenta na exploração e extração sem limites dos recursos naturais, os quais eram percebidos como infinitos (BECKER, 2009a, p. 24).

Entre o primeiro governo Vargas e o início do regime militar (1930-1966), não ocorreu nenhum planejamento efetivo para a região. Mesmo a criação da Superintendência de Valorização Econômica da Amazônia (SPVEA) não contribuiu para integrar efetivamente a região ao País. No entanto, a fronteira interna do País (que não coincide necessariamente com as fronteiras externas) aproximou-se da fronteira interna da Amazônia Legal. Segundo Becker, apenas entre 1966 e 1985 foi iniciado o planejamento efetivo da região (2009a, p. 25).

A ocupação efetiva passaria por rede de transportes, comunicações e produção de riquezas. Esta última baseava-se tanto no extrativismo tradicional, quanto no polo industrial da Zona Franca de Manaus (ZFM). As rodovias planejadas (Transamazônica e Perimetral Norte) também eram um componente fundamental desse esforço coordenado. O plano foi feito verticalmente, de cima para baixo. O último grande projeto desse periodo foi justamente o Calha Norte (1985), o qual foi levado adiante apenas pelo Exército Brasileiro. Segundo Becker tal planejamento não contemplou as especificidades locais. O planejamento - ainda 
longe da efetiva implementação na atualidade -, feito sem levar em conta diversas nuances como as populações locais, o território e a posição, teve desdobramentos profundos e em alguma medida negativos. Becker conclui afirmando:

O privilégio atribuido aos grandes grupos e a violência da implantação acelerada da malha tecno-política, que tratou o espaço como isotrópico e homogêneo, com profundo desrespeito pelas diferenças sociais e ecológicas, tiveram efeitos extremamente perversos [...]. Tais são lições de como não planejar uma região (BECKER, 2009a, p. 27)

Em suma, aqui valem as lições aprendidas nos clássicos acerca da arte da guerra e o planejamento estratégico. As linhas gerais são necessárias contudo, sem se perder a atenção nos detalhes e também há que se ter algum espaço para reavaliar o plano com correções devidas. Todo planejamento, para ser bem sucedido, precisa de um ajuste fino. Se o período dentro de uma cronologia que pensa a ocupação amazônica pelo País - até 1985 foi marcado por planejamentos distantes e verticais, o seguinte, que segue até hoje, não teve sequer um elemento norteador. Mesmo a iniciativa diplomática de elevar o TCA para OTCA, em 1998, aparentemente não foi seguida por investimentos maiores e coordenados sob um planejamento de Estado.

Resta, finalmente, a questão da 'governança', aplicada às considerações geopoliticas brasileiras acerca da Panamazônia. Essa ideia foi construida ao final do século $X X$.

A outra contribuição da NEI [Nova Economia Institucional] é a concepção e a difusão do conceito de governança. Incorpora a questão institucional na organização das transações econômicas, em que as empresas constituem os jogadores, definindo governança como o 'conjunto de regras que governa uma determinada situação' (WILLIAMSON, O., 1996). O conceito envolve interesses privados, não lucrativos e públicos (BECKER, 2009b, p. 39).

A governança parte do princípio da existência de outros atores agindo na região, além do estado. Assim, o poder - o qual não se arrenda, não se dá, não se conquista; só existe em ato quando exercido (FOUCAULT, 2005, p. 21) - é o resultante da ação e interação de grupos econômicos, sociedade civil, organizações não governamentais, organismos internacionais e Estados. Nos limitaremos aqui tão somente a indicar tal questão. Um estudo sobre governança na Panamazônia, abrangendo múltiplos atores, além do território e do povo, requer dados empíricos e reflexão profunda e cuidadosa. Não se pode pensar os habitantes locais apenas como uma categoria abstrata e genérica.

\section{Considerações finais}

Retornamos ao mapa imperial de Borges. A grandeza da nação projetou-se sobre todo o território. A geopolítica brasileira almejava traçar caminhos para o País tornar-se potência. AAmazônia seria uma reserva estratégica para tal caminho. Um aspecto que salta aos olhos é a antinomia Brasil/ Amazônia. Quer parecer que esta não é uma parte integrante da nação brasileira. Seria, portanto, um departamento colonial do Brasil?

Nos escritos geopolíticos apresentados aqui, a Amazônia desloca-se entre dois eixos bem definidos: defesa e desenvolvimento. Em ambos, fica claro que o Estado brasileiro é o agente e o território amazônico, o paciente. Deve-se proteger a região amazônica da cobiça estrangeira, pois é um grande repositório de recursos. Esses levariam o País ao desenvolvimento. O desenvolvimento da região, por outro lado, também favoreceria a defesa da mesma.

O mote "A Amazônia é brasileira!" é um sintoma muito revelador. Em primeiro lugar, estabelece dois sujeitos, Amazônia e Brasil. Não se ouve falar se outras regiões brasileiras o são efetivamente. Não há dúvidas. A insistência em reafirmar o mote, mais do que uma exprimir uma certeza, quer parecer uma insegurança. A segunda inferência possivel acerca desse mote é sobre como uma efetiva integração ocorreria, se de maneira uniforme ou de modo colonizador. A resposta para tanto só poderá surgir de políticas efetivas de integração de povo e território, conferindo cidadania efetiva aos habitantes amazônicos. 
Mutatis mutandi, tão problemático quanto uma classe intelectual falar em nome dos desvalidos, também o é pensar soluções de integração, defesa ou desenvolvimento para a região amazônica sem envolver os atores locais, da sociedade civil à grupos econômicos; dos indígenas aos descendentes dos colonizadores e deportados.

Tal debate faz lembrar uma cena de filme onde uma família discute o destino do ancião - ou a casa de um dos filhos, ou o asilo - na frente do mesmo, como se ele não estivesse ali. Nós, brasileiros, refletindo sobre o que fazer com a Amazônia, território e população. A não integração da região amazônica ao território nacional fica patente sob tal narrativa. A Amazônia continuará funcionando como um protetorado? Ou, algum dia, será integrada de modo cidadão? Tal reflexão é essencial para a região.

\section{Referências}

ANDERSON, Benedict. Comunidades imaginadas: reflexões sobre a origem e a difusão do nacionalismo. São Paulo: Companhia das Letras, 2008.

ARGUELHES, Delmo de Oliveira. Protagonismo diante da prudência: breves apontamentos acerca da segurança regional. In: OLIVEIRA, Marcos Aurelio Guedes de. (org.). Cultura de defesa sul-americana. Recife: UFPE, 2013. p. 351-368. https://doi. org/10.26792/rbed.v5n1.2018.75027

BARTHES, Roland. Critica e verdade. São Paulo: Perspectiva, 1982.

BARTHES, Roland. Mitologias. 11. ed. Rio de Janeiro: Bertrand Brasil, 2001.

BECKER, Bertha. Amazônia: geopolítica na virada do III milênio. Rio de Janeiro: Garamond, 2009a.

BECKER, Bertha. O governo do território em questão: uma perspectiva a partir do Brasil. Parcerias estratégicas, Brasília, v. 14, n. 28, p. 33-50, 2009b.

BEVIR, Mark. A lógica da história das ideias. Bauru: Edusc, 2008.

BORGES, Jorge Luis. Obras completas, volume II 1952-1972. São Paulo: Globo, 1999.

CARR, Edward Hallett. Vinte anos de crise: 1919-1939 Brasilia: Edunb, 2001.

CARTIER, Michel. Impérios. In: ENCICLOPÉDIA EINAUDI - volume 14: Estado - Guerra. Tradução de António Perestrelo de Matos et al. Lisboa: Imprensa Nacional / Casa da Moeda, 1989. p. 318-29.

CARVALHO, Carlos Delgado de. História diplomática do Brasil. Brasilia: Senado Federal, 1988.
CASTRO, Terezinha de. Nossa América: geopolitica comparada. Rio de Janeiro: Bibliex, 1994

CASTRO, Terezinha de. Geopolitica: principios, meios e fins. Rio de Janeiro: Bibliex, 1999

CERVO, Amado Luiz. Inserção internacional: formação dos conceitos brasileiros. São Paulo: Saraiva, 2008.

DARDEL, Eric. O Homem e a Terra: natureza da realidade geográfica. São Paulo: Perspectiva, 2011.

DUROSELLE, Jean-Baptiste. Todo império perecerá: teoria das relações internacionais. Brasilia / São Paulo: Edunb / Imprensa Oficial, 2000. https://doi. org/10.1590/s0034-73292000000200018

FOUCAULT, Michel. Em defesa da sociedade: curso no Collège de France (1975-1976). São Paulo: Martins Fontes, 2005. https://doi.org/10.11606/issn.21768099.pcso.2001.75756

FREEDEN, Michael. Ideologies and political theory: a conceptual approach. Oxford: Clarendon Press, 2008.

GADAMER, Hans-Georg. Verdade e método I: traços fundamentais de uma hermenêutica filosófica. 5. ed. Petrópolis: Vozes, 2003.

GADAMER, Hans-Georg. Verdade e método Il: complementos e indice. Petrópolis: Vozes, 2002

HEIDEGGER, Martin. Ser e tempo. Petrópolis / Bragança Paulista: Vozes / São Francisco, 2006.

HITLER, Adolf. Minha luta. 5. ed. Tradução de Klaus von Puschen. São Paulo: Centauro, 2005.

HOUAISS, Antônio; VILLAR, Mauro de Salles; FRANCO, Francisco Manoel de Mello. Dicionário Houaiss da lingua portuguesa. Rio de Janeiro: Objetiva, 2009. https://doi.org/10.17979/rlex.2003.9.0.5582

HUSSERL, Edmund. A ideia da fenomenologia. Lisboa: Edições 70, 1986

GINZBURG, Carlo. Mitos, emblemas, sinais: morfologia e história. São Paulo: Companhia das Letras, 1991.

KUHN, Thomas. A estrutura das revoluções cientificas. 5. ed. São Paulo: Perspectiva, 1997.

MEIRA MATTOS, Carlos de. Geopolítica - volume 1. Rio de Janeiro: Bibliex / FGV, 2011a.

MEIRA MATTOS, Carlos de. Geopolítica - volume 2. Rio de Janeiro: Bibliex / FGV, 2011b.

MEIRA MATTOS, Carlos de. Geopolitica - volume 3. Rio de Janeiro: Bibliex / FGV, 2011C.

MÉSZÁROS, István. O poder da ideologia. São Paulo: Boitempo, 2004

MONTESQUIEU, Charles de Secondat, Barão de. O espirito das leis. 2. ed. Tradução de Cristina Murachco. São Paulo: Martins Fontes, 1996. 
ORGANIZAÇÃO DO TRATADO DE COOPERAÇÃO AMAZÔNICA. O tratado de cooperação amazônica 2013. Disponivel em: http://www.otca.info/portal/tratado-coop-amazonica.php?p=otca. Acesso em: 24 jun 2013. https://doi.org/10.18227/1983-9065ex.v3i1.1493

RENOUVIN, Pierre; DUROSELLE, Jean-Baptiste. Introdução à história das relações internacionais. São Paulo: Difel, 1967.

RONCAYOLO, Marcel. Território. In: ENCICLOPÉDIA EINAUDI - volume 8: região. Tradução de Maria do Céu Gomes. Lisboa: Imprensa Nacional / Casa da Moeda, 1986. p. 161-89.

SEEMANN, Jörn. Tradições humanistas na cartografia e a poética dos mapas. In: MARANDOLA Jr., Eduardo; HOLZER, Werther; OLIVEIRA, Livia de (org.). Qual o espaço do lugar? Geografia, epistemologia, fenomenologia. São Paulo: Perspectiva, 2012. p. 69-91.

ZIENTARA, Benedikt. Fronteira. In: ENCICLOPÉDIA EINAUDI, volume 14: Estado - Guerra. Lisboa: Imprensa Nacional / Casa da Moeda, 1989. p. 306-17.

ŽIŽEK, Slavoj (org.). Um mapa da ideologia. Rio de Janeiro: Contraponto, 1996.

\section{Delmo de Oliveira Torres Arguelhes}

Doutor em História das Ideias e Historiografia, Universidade de Brasilia (UnB); Professor do Curso de Mestrado em Direitos Humanos, Cidadania e Violência do Centro Universitário Euro Americano (UniEURO); Brasília, DF, Brasil.

\section{Endereço para correspondência}

Campus UniEURO Asa Sul: Avenida das Nações, Trecho 0, Conjunto 05 - Brasilia - DF. 70.200-001. 